\title{
A phyto-guide to species selection for optimized South African green infrastructure
}

\author{
DM Jacklin', IC Brink¹ and SM Jacobs ${ }^{2 \dagger}$ \\ 'Department of Civil Engineering: Water and Environmental Engineering Group, Stellenbosch University, Private Bag X1, \\ Matieland 7602, South Africa \\ ${ }^{2}$ Department of Conservation Ecology and Entomology, Stellenbosch University, Private Bag X1, Matieland 7602, South Africa \\ ${ }^{\dagger}$ deceased
}

In South Africa, rapid environmental degeneration caused by anthropogenic pollution poses a major ecological engineering problem, demanding proper resource mitigation strategies. For the treatment of polluted water and degraded soil systems, green infrastructure (GI) offers an effective, sustainable and affordable nature-based alternative to grey infrastructure. An additive benefit within $\mathrm{Gl}$, plant species provide enormous potential to treatment; however, species vary substantially in their pollutant removal and hydrologic performance. South African civil engineers tasked with designing Gl often lack expertise and knowledge of plant behaviour and ecosystem dynamics. Therefore, this paper proposes a decision framework to facilitate selection for designing local GI in the form of a phyto-guide, based on existing recommendations and knowledge of removal processes and plant behaviour. Interdisciplinarity at the core of the phyto-guide relies on continuous specialist collaboration with each selection criteria, whilst efficiency and sustainability are considered equally important contributors to successful GI functioning. The spread of invasive alien plants, whether accidental or deliberate, negatively impacts an ecosystem's capacity to deliver goods and services. Thus, the desire to optimize GI by incorporating effective phytoremediators cannot be prioritised over conservation concerns. In addition, this paper seeks to advance the Gl limitation of relying solely on previously identified phytoremediators, by including evaluation criteria of beneficial plant traits as well as plant distribution, behaviour and diversity into the decision-making process for optimized GI. It is recommended that future research engages in discovering less invasive, naturally occurring local species as potential phytoremediators, inspired by South Africa's rich biodiversity and endemism, as well as conveying the importance of consultation with engineers and ecologists for optimized Gl.

\section{INTRODUCTION}

Pollution of the South African biosphere by anthropogenic organic and inorganic materials, and heavy metals, has resulted in the release of large amounts of contaminants to urban and rural soil and water resources, posing a major human and environmental health problem (Nomquphu et al., 2007; Govender et al., 2011; Constantine et al., 2014; Malan et al., 2015). Due to urbanisation, agriculture, industry, mining, waste disposal, dysfunctional sewage works and unsewered formal and informal human settlements, South Africa is experiencing some of the most rapid environmental degradation globally, requiring proper mitigation strategies to restore ecosystem function and improve resource quality (Oberholster and Ashton, 2008; De Klerk et al., 2016).

Internationally, nature-based solutions have been demonstrated to provide critical maintenance, rehabilitation and purification services to degraded areas in a more cost-effective way than traditional solutions, with research in this domain receiving significant scientific and commercial attention (Postel and Thompson, 2005; Peuke and Rennenberg, 2006). Green infrastructure (GI) offers a sustainable yet effective approach for, inter alia, the on-site treatment of stormwater and amelioration of degraded soil systems, as well as playing an integral role in various rehabilitation efforts, thus conserving dwindling natural resources (Hufnagel and Rottle, 2014; Choudhary et al., 2015; Yang et al., 2015; Wirth et al., 2018). GI is the interconnected set of natural and engineered ecological systems on different spatial levels that cooperatively produce valuable services in areas such as energy, security, climate regulation, aesthetics and resource management, in an efficient and self-sustaining way, promoting a versatile nature-based alternative to grey infrastructure (Cole et al., 2017; Pauleit et al., 2017; Pasquini and Enqvist, 2019). If implemented correctly, GI has the potential of eventually being more sustainable than traditional solutions, as well as providing a range of ecosystem services to society (Kitha and Lyth, 2011; Wertz-Kanounnikoff et al., 2011). These services mitigate the growing risks associated with grey infrastructure, rapid urban development and climate change, aiding general urban sustainability through water filtration, storage and recycling (Culwick et al., 2016; Pasquini and Enqvist, 2019).

Within GI, selected plant species are used for the in-situ treatment of environmental pollutants, a process known as phytoremediation, by improving water quality compared with unvegetated soil media (Dietz and Schnoor, 2001; Denman et al., 2006; Henderson et al., 2007). Phytoremediation is a relatively inexpensive yet effective form of ecological engineering utilising plants to detoxify, degrade and/or remove pollutants from the environment, effectively restoring and ameliorating degraded environments (Terry and Bañuelos, 1999; Meagher, 2000; Visoottiviseth et al., 2002).

\section{CORRESPONDENCE}

IC Brink

\section{EMAIL}

icbrink@sun.ac.za

\section{DATES}

Received: 12 January 2021

Accepted: 24 September 2021

\section{KEYWORDS}

green infrastructure ecological engineering phytoremediation phytotechnologies practical guide

\section{COPYRIGHT}

(c) The Author(s)

Published under a Creative Commons Attribution 4.0 International Licence (CC BY 4.0) 
Plant selection has a substantial influence on GI performance, due to varying pollutant removal efficiencies affected by environmental, physiological and morphological inconsistencies between species (Read et al., 2008; Read et al., 2010). During the planning and design process of GI, the devised set of green networks, distributed throughout the urban area for site-specific pollutant remediation, ecosystem functioning and risk attenuation, are required to meet specific infrastructure and service needs with the local natural habitat in need of remediation considered (Ahern, 2007). The addition of ecosystem value assessment for both rural and urban areas allows for the implementation of fit-for-purpose, sustainable yet effective infrastructure solutions (Culwick et al., 2016). Vital to GI success is the appropriate design and spatial distribution of green networks, due to the diffuse nature of pollutant influent received (Brink, 2019). Optimal GI design is complex and requires both engineering hydrology knowledge and insights into the functioning of natural elements, not generally included in the typical training of the practicing engineer (Brink, 2019). This amalgamation of knowledge for scientifically backed design can only be achieved by embracing collaboration with a range of local specialists integrating disciplines from engineering, planning and science (Wong, 2006; Tanner and Möhr-Swart, 2007; Davis et al., 2009; Armitage et al., 2014).

The recognition of ecosystem services and its value to human health in South Africa (Le Maitre et al., 2007) has initiated a growing movement towards the acceptance of the water-sensitive urban design (WSUD) philosophy, which has the potential to mitigate the negative effects of water scarcity, manage and reverse water pollution, increase sustainability, and develop resilience to natural disasters and climate change within water systems (Armitage et al., 2014). Within WSUD, the augmentation of knowledge and skills by the practicing engineer represents a holistic approach to stormwater engineering, promoting stormwater management through sustainable (urban) drainage systems (SuDS) (Armitage et al., 2014). Although the WSUD framework provides philosophical guidance, it does not yet provide design specifics; similarly, the SuDS component focuses on the management of stormwater rather than design specifics (Brink, 2019). A concerning trend has emerged during planning and application in South Africa as a direct result of a lack in design guidelines complicating implementation, which is that GI is perceived as a new concept that does not yet fit into established municipal guidelines (Pasquini and Enqvist, 2019). Thus, increasing emphasis is placed on expanding knowledge, skills and support to engineers that are frequently tasked with selecting and designing appropriate GI, based on complex engineered solutions within dynamic natural processes for remediation success (Culwick et al., 2016).

Therefore, this paper builds on existing recommendations and knowledge to provide a strategic guide to the South African practicing engineer for the appropriate selection of plant species to optimize GI remediation technologies, at the same time limiting injudicious plant introduction into engineered designs and natural ecosystems. In supporting GI feasibility, the proposed phyto-guide regards remediation efficiency and sustainability as equal contributors to success, thus including plant ecology and conservation together with the other disciplines throughout the design process. In addition to species presence in global bioremediation literature, distribution, invasiveness, conservation status and behaviour, the phyto-guide considers plant physiological characteristics such as growth and vegetative expansion, natural tolerance for extreme environmental and climatic conditions, and hardiness to biotic and abiotic stresses (where such information is available). Furthermore, plant morphological traits are assessed, with biomass and root characteristics contributing to pollutant remediation efficiency (Ghosh and Singh, 2005; Read et al., 2010). Due to the importance of biodiversity and aesthetics, the combination of effective phytoremediators with desirable traits, and non-invasive less effective phytoremediators with some but not all desirable traits, is explored, encouraging diversity of species and species traits in GI projects.

\section{RATIONALE FOR SELECTION OF FACTORS INLUENCING GI PERFORMANCE}

In an effort to optimize GI, factors determining potential plant selection can be grouped into the following broad categories: species presence in global bioremediation literature; distribution, invasiveness and conservation status; physiological characteristics and responses; morphological traits; and heterogeneity and aesthetics.

\section{Species presence in global bioremediation literature}

Bioremediation literature provides valuable information on proven effective phytoremediators, along with their associated pollutant affinities, to the GI designer, who can select potential species on the basis of removal efficacy, distribution or invasiveness, for use in site-specific remediation initiatives. In assessing reported literature, though limited to case-specific bioremediation research, the practicing engineer is supplied with information on effective species and their target pollutants. Bioremediation studies of importance include investigations of stormwater quality improvement, sustainable urban drainage systems, water-sensitive urban design, low-impact development systems, water and soil rehabilitation initiatives and reported plant encounters in metal-rich environments.

\section{Plant distribution, invasiveness and conservation status}

The introduction of invasive exotic phytoremediators to remediation initiatives alters the natural environment and may increase the threat of biological invasion, thereby impeding GI function (Budelsky and Galatowitsch, 2004) and increasing ecological risk (Leguizamo et al., 2017). Thus, endemic or indigenous species capable of adapting to the recipient habitat, enhancing remediation performance and limiting the risk of biodiversity loss by alien invasion, are considered (Oversby et al., 2014). These species are naturally distributed to a region and have established themselves in the environment without human assistance (Leguizamo et al., 2017). For example, in South Africa Agapanthus africanus and Alectra sessiliflora are representatives of endemic and indigenous phytoremediator species, respectively (see Jacklin et al., 2021).

The introduction of invasive alien plants (IAPs) often negatively affects the recipient natural ecosystems, generating massive economic losses, and causing a major environmental problem (Van Wilgen et al., 2001). For instance, introduced IAPs may disturb local vegetation, jeopardizing existing mutualistic edaphic networks, thereby limiting an ecosystem's natural capacity for resilience and recovery (Montes et al., 2007; Rodríguez-Echeverría, 2009). The difficulty, however, is that many behavioural properties advantageous for phytoremediation are shared with invasiveness (Leguizamo et al., 2017). Thus, to reduce the threat of invasion, the use of non-invasive species should always be promoted (Payne et al., 2015). The use of species of little or no conservation concern, which are generally more abundant and available than species in short supply or at risk of extinction, enhances practicability of GI initiatives (Visoottiviseth et al., 2002). However, there are instances in complex GI situations where vulnerable species offer potential for use, due to their delicate local inter-species relationship and ease of adaptation to the recipient habitat (Barbier et al., 1997).

The demand for vulnerable species (in low abundance naturally or due to degradation) may strengthen their population numbers and enhance species survival (Prasad, 2004). It is paramount that species experiencing dwindling population numbers, and 
in danger of extinction, are only considered along with or following sustained conservation initiatives, in consultation with conservation ecologists and botanists, to mitigate their vulnerability and potential invasiveness.

\section{Plant physiological characteristics and responses}

The ability of vegetation to acclimate after introduction plays an important role in new GI projects, influencing the system's resilience, recovery and remediation efficiency (Payne et al., 2015). In different ecosystems species are exposed to varying climatic and habitat conditions and species selection must reflect this change to hinder dormancy in species not accustomed to the applicable conditions, as well as increase productivity through species diversity (Leguizamo et al., 2017). Establishment success and long-term GI efficiency is influenced by plant growth rate, their ability to tolerate water stress during periods of drought by regulating opening and closing of the stomata (Arve et al., 2011), maintaining plant maturation rate and supporting effluent runoff infiltration into the growth media (Farrell et al., 2013). In addition, an inherently fast growth rate is a performance trait advantageous in wet conditions, contrasting with species of slower growth which are better performers in dry conditions (Oversby et al., 2014).

Similarly, appropriate plant lifespans vary according to specific site conditions and intended target pollutants (Roca et al., 2017). For instance, plants naturally distributed on metalliferous soils with shorter lifespans are frequently equipped to phytoremediate heavy metal pollution, although not all heavy metals are removed to the same extent, emphasizing the importance of species choice (Visoottiviseth et al., 2002). Traditionally, plants with longer lifespans and high growth rates are preferred for sustainability; however, plants with a shorter lifespan and high growth rate are preferred for heavy metal remediation in metalliferous soils (Visoottiviseth et al., 2002; Leguizamo et al., 2017). A short lifespan assisted by rapid growth encourages metal hyperaccumulation, by exposing the plants to greater toxicity and with time resulting in plant mortality (Salt et al., 1998; Conesa et al., 2009).

The ability of GI to prevail in extreme climatic conditions by tolerating intermittent periods of rainfall, drought and flood events is improved with appropriate plant selection (Oversby et al., 2014). Thus, variation in local rainfall and seasonal patterns require species accustomed to both periods of drought and inundation, which may reduce the system's efficiency if not engineered properly (Robinson et al., 2015).

\section{Plant morphological traits}

Morphological traits for water quality improvement have been found to correlate with some highly specialized physiological functions, confirming the importance of intricately selecting species with appropriate traits to GI systems (Payne et al., 2015). Morphological traits known to enhance phytoremediation efficiency and ultimately the performance of GI are above- and below-ground plant biomass, as well as root composition (Visoottiviseth et al., 2002; McGrath and Zhao, 2003; Read et al., 2010). Root systems composed of deep, fibrous and large biomass roots, with a high root:shoot ratio within the biofilter growth media, influence pollutant interaction and support microbial communities (Read et al., 2008; Oversby et al., 2014). Although the removal performance of plants with thick taproots differ from species with abundant fibrous roots, thick roots create macropores throughout the filter media which assist with infiltration (Hatt et al., 2009).

\section{Heterogeneity and aesthetics of green infrastructure}

Due to the dynamic processes affecting appropriate species selection, as well as their varying efficiencies over a range of pollutants, vegetative combination contributes to GI water quality and infiltration performance (Read et al., 2010). An approach to enhance vegetative heterogeneity combines known effective phytoremediators with desirable physiological and morphological traits as a majority, with some less effective species exhibiting some but not all desirable traits, to achieve GI optimization throughout fluctuating seasons and environmental conditions (Oversby et al., 2014). Support of the local community, the relevant stakeholders and beneficiaries is more easily obtained by aesthetically pleasing GI systems, contributing to the importance of such heterogeneous species mixes. During design, the engineer must seek to incorporate the local context through the potential use of efficient local species supporting biodiversity, which provide diversity and habitat to enhance microclimate benefits, whilst serving as visually stimulating attractions (Payne et al., 2015).

The effect of natural factors influencing a dynamic resident biota as well as its prevailing site and climatic conditions must be considered in order to account for potential invasiveness within an ecosystem (Richardson et al., 2020). Thus, specialist collaboration from a number of disciplines within science and engineering promotes the amalgamation of knowledge required for the creation of a design science for GI.

\section{UNPACKING THE PHYTO-GUIDE PROCESS FOR SOUTH AFRICA}

In South Africa civil engineers frequently tasked with the optimization of sustainable GI technologies, equipped with typical engineering hydrology knowledge, may lack the necessary insights into the functioning of natural ecosystems. Thus, to facilitate species selection during GI planning and design, the phyto-guide provides the user with a decision-framework for the appropriate selection of South African plant species. This selection process considers removal efficiency and sustainability as equally important factors for successful GI technologies, facilitating greater accuracy in risk assessments of introduced species. Although the process of considering these factors is vital during planning and design for the optimization of all GI technologies, here we present the systematic plant selection process, together with relevant sources, in the South African context only.

\section{Applying the phyto-guide}

The phyto-guide for appropriate species selection during planning and design consists of five main categories influencing selection, with each step requiring input from relevant specialists (Fig. 1). The initial step of the process relies on the user's ability to conduct a literature investigation of published bioremediation research to identify proven effective phytoremediators as potential candidates. This step is, however, not critical to the phyto-guide's success and can be bypassed by commencing with the second selection step - evaluating reported distribution, invasiveness and conservation characteristics of species from various readily available herbarium records and online databases. This step requires specialist input from the fields of botany, ecology and invasion biology. In continuing the selection process, the third step considers the physiological characteristics of species identified thus far, as indicators of potential efficacy in remediation initiatives. Here collaboration with specialists such as ecologists, invasion biologists, soil scientists and environmental scientists is crucial to account for complex interactions with resident biota, ecosystem dynamism as well as potential invasiveness, due to rapid growth and vegetative expansion, hardiness and disease and pest resistance - all desired traits for phytoremediation. The penultimate step, largely aided by the botanist and ecologist, assesses the morphological traits of potential species as indicators for remediation. Similar to plant physiology, the desired morphological traits vary according to 
ecosystem conditions and the pollutant of concern, with heavy metal accumulators markedly different in biomass as opposed to nutrient phytoextractors. Finally, with species thoroughly assessed, the phyto-guide process seeks to include a combination of effective and less effective species to stimulate an appealing, biodiverse and sustainable system, requiring input from urban planning and landscape architecture to achieve GI heterogeneity and aesthetics. In concluding the process, collaboration with all specialists is sought, achieving planning interdisciplinarity for effective yet sustainable GI solutions.

\section{Identifying South African phytoremediators from literature}

In assessing potential phytoremediator species for use in sitespecific GI projects, the most valuable source of information at the engineer's disposal is available literature on the topic of bioremediation. The scope of available published global bioremediation literature in the form of peer-reviewed articles, books, reports, case studies, conference proceedings, theses and dissertations, as well as online databases, allows for the identification of proven efficient phytoremediators and their associated pollutants for use in GI. This dataset continuously grows and is refined with the addition of new evidence, allowing more reliable assessment of the capabilities of potential phytoremediators.

For this reason, the initial step of the phyto-guide framework requires the responsible engineer to perform a literature investigation of previously reported findings, accessible from scholarly literature sources across an array of published formats and disciplines, as well as compiled online databases (Famulari, 2011; CMLR, 2017). Species classified as less efficient phytoremediators, although undesirable based on remediation efficiency, are not rejected for use as they may contribute to the system's heterogeneity and aesthetics, promoting GI diversity. In a concurrent study exploring potential Western Cape (South Africa) plant species for polluted water and soil phytoremediation, the authors applied the phyto-guide and successfully processed data from 800 literature sources and 2 online databases. At the time of writing, the database had recorded 4171 data entries, encompassing 1410 species from 582 genera with 136 subspecies and variants, with 257 indigenous or naturalised South African species, of which 56 endemic or indigenous species were phytogeographically distributed in the Western Cape; the smaller subset are all non-invasive and of least conservation concern (Jacklin et al., 2021).

Although findings from the literature investigation will potentially supply the phyto-guide user with knowledge of proven phytoremediator species for distribution-, invasiveness- and vulnerability-assessments with regard to the individual recipient site, the phyto-guide's success does not solely rely on this step. For instance, if the user is ill-equipped to initiate a literature investigation, information on efficient phytoremediators is lacking, or if the habitat, environmental or climatic conditions within the recipient site in need of remediation do not support the proposed species, the user may bypass the initial literature investigation and commence with the plant distribution assessment as illustrated (Fig. 1).

\section{Assessing distribution, invasive status and vulnerability to extinction}

Due to the risk of native biodiversity loss, species within the recipient habitat can be identified by assessing their phytogeographic distribution and herbarium records from the South African Indigenous Plants Catalogue (SAIPC: Random Harvest, 2020), the International Union for the Conservation of Nature Red List of Threatened Species (IUCN, 2020), the South
African National Biodiversity Institute's Red List of South African Plants (SANBI, 2020b) and Plants of Southern Africa (SANBI, 2020a). In addition to evaluating the herbarium records, the aid of conservation specialists who may have a greater understanding of the ecosystem processes within the habitat in need of remediation must be sought.

In the interest of sustainability, species displaying invasiveness, whose introduction may threaten GI longevity, are disregarded by the phyto-guide based on local and international standards, as well as being reported in regional and online databases from the International Invasive Species Compendium (CABI, 2020), the Invasive Species Specialist Group Global Invasive Species Database (ISSG, 2020), the Alien Invasive Plant List for South Africa (AIPLSA, 2019), the National Environmental Management: Biodiversity Act, 2004 - Alien and Invasive Species List (NEM:BA, 2004), the Status of Biological Invasions and their Management in South Africa (Zengeya and Wilson, 2020), Biological Invasions in South Africa (Van Wilgen et al., 2020), the Information Retrieval and Submission System of the Centre of Excellence for Invasion Biology (CIB, 2020) and the South African Plant Invaders Atlas (SAPIA: ARC, 2020). All species listed by NEM:BA under invasive categories $1 \mathrm{a}, 1 \mathrm{~b}, 2$ or 3 , as described below, are excluded for use in South African GI technologies. Category 1a stipulates all species for which the person in control must take immediate steps to combat or eradicate the invasive species, with Category $1 \mathrm{~b}$ enforcing the person in control to contain the invasive species. Category 2 species requires that the individual that carries out the effective control of the invasive within a specified area be in possession of the appropriate permit. Species listed as Category 3 are subject to exemptions and prohibitions as specified by NEM:BA, Act No. 10 of 2004 (RSA, 2004), and may consider registered species occurring in riparian areas for Category $1 \mathrm{~b}$ management as above. In terms of conservation status, the phyto-guide considers abundant and available species of least conservation concern only, as listed in the South African National Biodiversity Institute's Threatened Species Programme (SANBI, 2020c), and International Union for the Conservation of Nature's Red List of Threatened Species (IUCN, 2020) records.

\section{Evaluating appropriate physiological characteristics}

The appropriate growth rate, ability to proliferate and lifespan exhibited by potential species varies with habitat conditions and target pollutants. Species exhibiting rapid growth and population expansion have been found to exhibit greater performance during wet conditions, with species exhibiting low growth and expansion better equipped during dry conditions. For habitats experiencing seasonal climatic fluctuation, species with more moderate growth and expansion are preferred. In addition, species with rapid and moderate growth rate, with longer lifespans such as some monocarpic and polycarpic plants, support GI sustainability and longevity, whereas plants with a rapid growth rate and shorter lifespan, such as annuals, biennials and some perennials, reach maturity faster and are preferred for toxic heavy metal accumulation. Exposing hyperaccumulating plants to toxic pollutants will result in plant mortality. If the objective of the GI project is to establish a community, the phyto-guide attempts to include a combination of growth rates and lifespans for strengthening diversity, with rapidly maturing, longer-lived species an attractive option for promoting vegetative establishment of new GI systems, whilst the shorter-lived metal-accumulating species require a harvesting and removal maintenance plan, before the extracted toxins are deposited back into the system after plant mortality. In the absence of heavy metal pollution, annuals are not considered effective phytoremediators, with slow-growing succulents only contributing to GI in diversity and heterogeneity. 


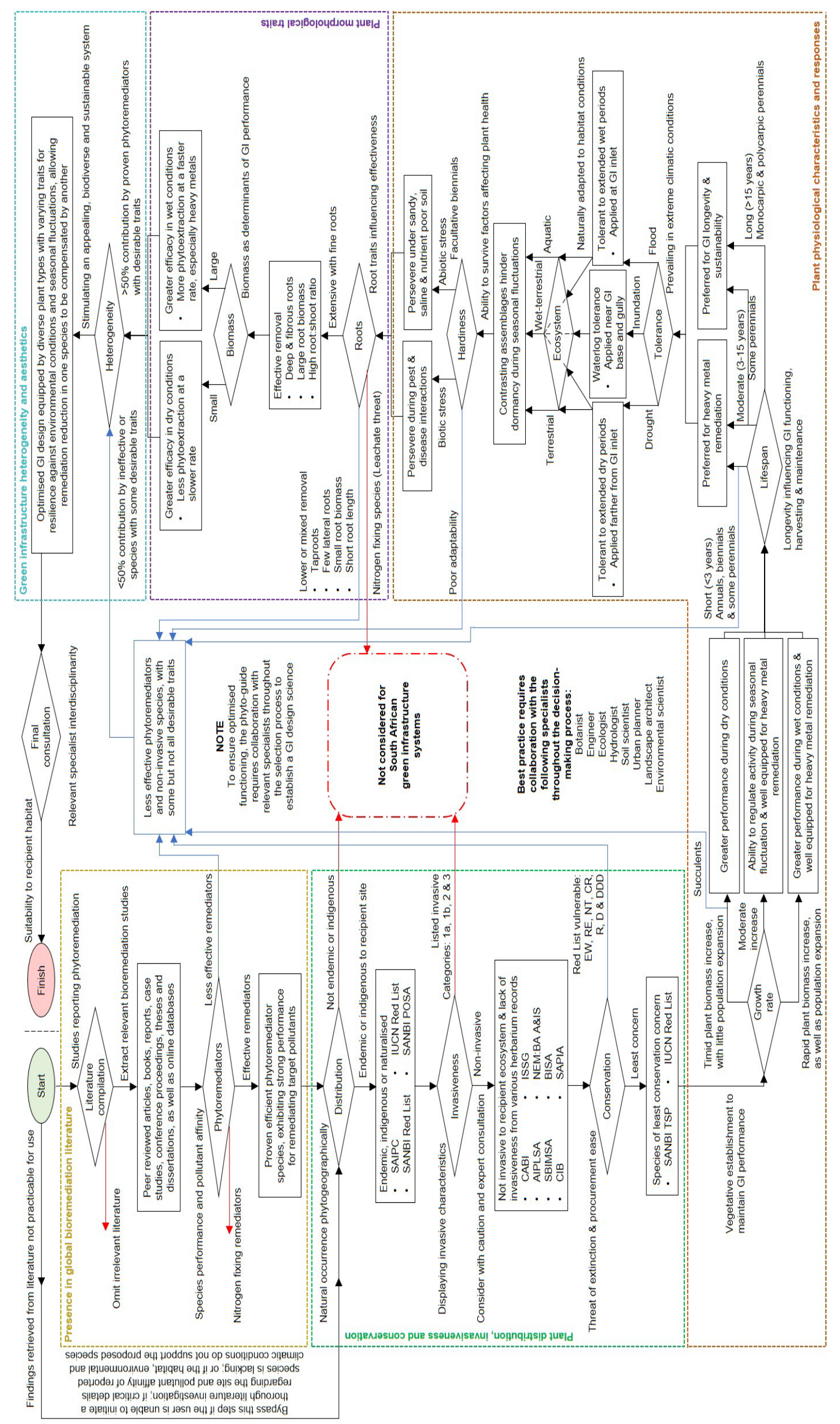

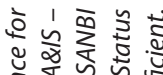

\%ั้

这然

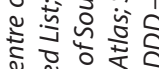

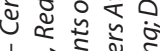

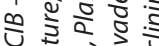

旅

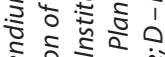

हैं 흘

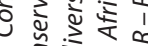

造

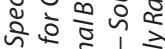

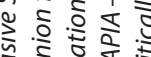

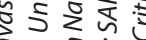

ह 하 है

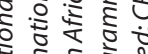

क्षे के क्ष

ํํㅇํำ

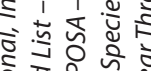

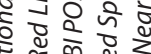

(1)

ร

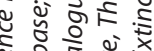

政

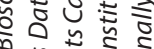

원

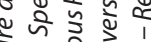

5े 은

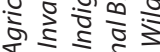

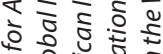

은

온

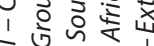

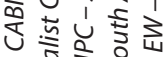

列空

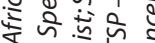

5

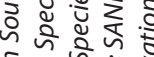

s o

을

政

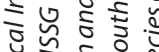

을

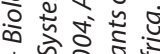

तㄷำ

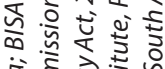

记

은

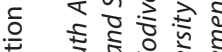

응 웧

흘 हैं के

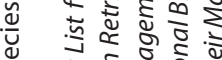

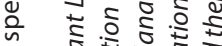

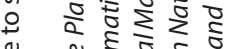

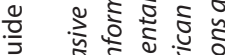

क人

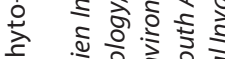

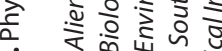

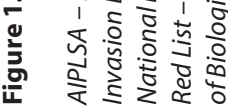


Performance in extreme climatic and habitat conditions, as well as prevalence under biotic and abiotic stress, is evaluated by assessing species' tolerance to sustained periods of drought and inundation, rhizospheric change with increased salinity, poor nutrient and sandy media, and resistance to pests and diseases. Species accustomed to waterlogged roots are expected to proliferate at or near the GI inlet or base, as these areas are prone to saturation, with areas further away or upslope from the saturated zone drier, and plant selection as well as planting location must reflect this distinction between terrestrial, wetterrestrial and aquatic species affinity. The phyto-guide includes species' natural growth environments, where their ability to thrive in specific habitat conditions provides a rationale for assuming adaptability to various climatically and nutritionally challenging sites, supporting candidates less susceptible to stress. For instance, certain metal hyperaccumulators thrive in heavily contaminated environments which others would find too harsh, inferring their use as resilient species in harsh conditions.

\section{Morphological traits as performance indicators}

In assessing morphological traits for potentially novel phytoremediators, species displaying extensive root systems with deep and fibrous roots, a large root biomass and a high root:shoot ratio provide contact with the pollutants in the rhizosphere, improving remediation efficiency, and are favoured for use. Highly fibrous roots within the rhizosphere growth media, where pollutant interaction occurs, support large microbial communities which promote pollutant degradation, uptake and ultimate extraction by the root system. Species with inefficient root systems, i.e., taproots and few lateral roots, small root biomass and short root length, do not notably aid in establishing new GI systems but will contribute to remediation efficiency with time, as differences in root biomass among species are diminished as plants mature and GI longevity is improved by taproots hindering clogging. The phyto-guide avoids nitrogen-fixing species due to a potential nitrogen saturation threat (Payne et al., 2015). In addition to plant roots, the phyto-guide assesses plant biomass as another morphological indicator of phytoremediation capacity. Species with a large total biomass, recognized for their intense phytoextraction capabilities and rapid growth with large root masses, possess greater efficacy in wet conditions, especially for the remediation of heavy metals. Species with slower growth, low above-ground plant biomass and reduced leaf mass exhibit a lower phytoextraction rate and are better performers during dry conditions. This relationship between morphology and habitat further enhances the need for heterogeneity, with diverse root structures, including grasses, sedges, rushes, shrubs and, to a lesser extent, trees, increasing GI diversity.

\section{Optimizing GI through heterogeneity}

In concluding the phyto-guide selection process, species identified as proven phytoremediators, with relevant distribution and behaviour, and appropriate physiological characteristics and morphological traits, are recommended to comprise at least $50 \%$ of GI projects, with the less effective remediator species with some desirable traits comprising less than 50\% (Oversby et al., 2014). This strategy maintains treatment efficiency whilst diversifying plant types with varying traits for resilience against environmental conditions and seasonal fluctuations, allowing low ability for remediation in one species, as well as periodic dormancy during seasonal change to be compensated by another. The addition of species temporarily omitted due to absence of evidence as effective phytoremediators from literature, threat of extinction, poor adaptability to stress, short lifespan and timid root traits, will contribute to GI's runoff infiltration capacity, sustainability and success by supporting local biodiversity and aesthetics.
The use of both effective phytoremediators with desirable traits and ineffective phytoremediators with less desirable traits stimulates a diverse, efficient and visually appealing system, for individual site-specific conditions.

During the phyto-guide decision-making process, the practicing engineer assessing plants for potential introduction in GI is required to consult and collaborate with relevant specialists in environmental science, field botany, conservation ecology, soil science, and landscape architecture, if aesthetic enhancement and phytoremediation is to be achieved. Although potential species are identified by investigating their phytogeographic distribution, invasiveness and vulnerability from herbarium records, input from specialists is crucial for the creation of GI design science for the phyto-guide's success, as indigenous non-invasive species may become invasive with introduction, or as conditions change. For instance, proposed species may still be of conservation concern to the specific habitat requiring remediation, as their introduction may disrupt natural complex and dynamic interactions.

\section{CONCLUSIONS}

Anthropogenic pollution of South Africa's resources has the ability to alter entire natural ecosystems, leading to degradation, and posing a major ecological engineering problem. GI offers a sustainable yet cost-effective treatment technology with plant choice having a substantial influence on treatment capacity and hydrological conditions. In South Africa, civil engineers are frequently tasked with selecting and designing appropriate GI, while often lacking expertise in plant behaviour and ecosystem dynamics.

The phyto-guide proposed here provides a decision framework for the practicing engineer to facilitate and enhance species selection during planning and design, for the consistent optimization and functioning of sustainable GI technologies. In considering factors associated with vegetative efficacy and consultation with a range of relevant specialists to avoid erroneous species selection, the phytoguide adopts interdisciplinarity as a fundamental principle, in order to establish an overarching planning approach for GI design science. Factors determining appropriate selection for optimized GI were species presence in global phytoremediation literature, their distribution, invasiveness and vulnerability, physiological characteristics, morphological traits, and heterogeneity and aesthetics, coupled with specialist collaborative input to develop a strategy reflecting recipient habitat conditions. The phytoguide considers factors influencing remediation efficiency and sustainability as equally important contributors to successful optimization and, although relevant to all GI, demonstrated the selection process within the South African context.

The phyto-guide promotes proven non-invasive indigenous South African phytoremediators of least conservation concern, inhabiting terrestrial or aquatic ecosystems, exhibiting appropriate plant growth, population expansion and tolerance to climatic and environmental conditions, with biomass and root characteristics as contributors to GI success. Selected proven effective phytoremediation species with desirable traits are recommended to occupy greater than $50 \%$ of the GI, with less effective phytoremediators and species containing some but not all desirable traits contributing less than $50 \%$. The combination of proven effective and ineffective species improves heterogeneity, diversifying plant types, behaviour and characteristics, equipping GI with resilience against a range of climatic conditions, allowing dormancy in one species to be compensated by another. The less desirable species with regard to phytoremediation efficiency contribute to GI sustainability and success by supporting local biodiversity and aesthetics, and stimulating a diverse and visually appealing system. In concluding the phyto-guide decision-making 
process, final consultation should include the following experts: wastewater and stormwater engineers, hydrologists, town and regional planners, disaster management practitioners, ecologists and soil scientists, environmental and municipal managers, and landscape architects.

Furthermore, the spread of IAPs causes a major environmental problem, jeopardising the recipient ecosystem and impairing the functioning of intricately designed GI. South Africa has a long history of alien invasion, with some species having transformed entire natural ecosystems, threatening the country's biodiversity and negatively impacting the ecosystem's capacity to deliver goods and services. Species promoted for use in GI may still be of conservation concern to the ecosystem requiring remediation, due to ecosystem dynamism, habitat processes, climate change, and prevailing environmental conditions. With the physiological characteristics contributing to efficient phytoremediation shared with potential invasiveness in ecosystems, e.g., rapid growth and vegetative expansion, hardiness and disease and pest resistance, as well as their complex interactions with resident biota, selected species may contribute to invasiveness. Thus, the desire to optimize GI technologies by introducing plant species for remediation cannot overshadow conservation. Failing to consider invasion threat during the planning and design process of both urban and rural GI remediation initiatives may lead to creating an artificial or altered environment in which alien species thrive, as urban areas are often the initial sites for introduction from which invasions spread. Due to the country's rich biodiversity, future projects must engage in studies of endemic South African plants as potential phytoremediators to minimize the potential invasive threat.

\section{ACKNOWLEDGEMENTS}

This research was funded by the National Research Foundation (NRF) Thuthuka Fund, with project identity: TTK180418322426.

\section{REFERENCES}

AHERN J (2007) Green infrastructure for cities: the spatial dimension. In: Novotny V and Brown P (eds) Cities of the Future: Towards Integrated Sustainable Water and Landscape Management. IWA Publishing, London.

AIPLSA (2019) Alien Invasive Plants List for South Africa, South Africa's national listed invasive species. URL: https://www.environment. co.za/weeds-invaders-alien-vegetation/alien-invasive-plants-list-forsouth-africa.html (Accessed 15 July 2020).

ARC (Agricultural Research Council, South Africa (2020) South African Plant Invaders Atlas (SAPIA), Agricultural Research Council: Weeds and Invasive Plants. URL: http://www.arc.agric.za/ arc-ppri/weeds/ (Accessed 15 July 2020).

ARMITAGE N, FISHER-JEFFES L, CARDEN K, WINTER K, NAIDOO V, SPIEGEL A, MAUCK B and COULSON D (2014) Water sensitive urban design (WSUD) for South Africa: Framework and guidelines. WRC Report No. TT 588/14. Water Research Commission, Pretoria

ARVE LE, TORRE S, OLSEN JE and TANINO KK (2011) Stomatal responses to drought stress and air humidity. In: Shanker A and Venkateswarlu B (eds) Abiotic Stress In Plants - Mechanisms and Adaptations. InTech Publishers, Rijeka.

BARBIER E, ACREMAN M and KNOWLER D (1997) Economic Valuation of Wetlands: A Guide for Decision-Makers and Planners. Ramsar Convention, Gland.

BRINK IC (2019) Small-scale dispersed green infrastructure - a fitting civil engineering solution to stormwater quality improvement? J. S. Afr. Inst. Civ. Eng. 61 (4) 42-49. https://doi.org/10.17159/23098775/2019/v61n4a4

BUDELSKY R and GALATOWITSCH S (2004) Establishment of Carex stricta Lam. seedlings in experimental wetlands with implications for restoration. Plant Ecol. 175 (1) 91-105. https://doi.org/10.1023/ B:VEGE.0000048102.72101.50

CABI (2020) Centre for Agriculture and Bioscience, International Invasive Species Compendium. URL: https://www.cabi.org/ISC (Accessed 20 July 2020).
CHOUDHARY MP, CHAUHAN GS and KUSHWAH YK (2015) Environmental degradation: causes, impacts and mitigation. In: National Seminar on Recent Advancements in Protection of Environment and Its Management Issues, February 2015, Rajasthan.

CIB (2020) Centre of Excellence for Invasion Biology, DSI-NRF Information Retrieval and Submission System. URL: https://ir.sun. ac.za/cib/community-list (Accessed 16 July 2020).

CMLR (2017) Centre for Mined Land Rehabilitation, Global Hyperaccumulator Database. URL: http://hyperaccumulators.smi. uq.edu.au/collection/ (Accessed 15 March 2020).

COLE LB, MCPHEARSON T, HERZOG CP and RUSS A (2017) Green infrastructure. In: Russ A and Krasny ME (eds) Urban Environmental Education Review. Cornell University Press, New York. https://doi.org/10.7591/cornell/9781501705823.003.0028

CONESA HM, MORADI AB, ROBINSON BH, KÜHNE G, LEHMANN E and SCHULIN R (2009) Response of native grasses and Cicer arietinum to soil polluted with mining wastes: implications for the management of land adjacent to mine sites. Environ. Exp. Bot. 65 (2-3) 198-204. https://doi.org/10.1016/j.envexpbot.2008.09.004

CONSTANTINE M, MUSINGAFI C and TOM T (2014) Fresh water sources pollution: A human related threat to fresh water security in South Africa. J. Public Polic. Gov. 1 (2) 72-81.

CULWICK C, BOBBINS K, CARTWRIGHT A, OELOFSE G, MANDER $M$ and DUNSMORE S (2016) A framework for a green infrastructure planning approach in the Gauteng City-Region. Volume No. 04. Gauteng City-Region Observatory, Johannesburg.

DAVIS AP, HUNT WF, TRAVER RG and CLAR M (2009) Bioretention technology: overview of current practice and future needs. J. Environ. Eng. 135 (3) 109-117. https://doi.org/10.1061/(ASCE)07339372(2009)135:3(109)

DE KLERK AR, OBERHOLSTER PJ, VAN WYK JH, TRUTER JC, SCHAEFER LM and BOTHA AM (2016) The effect of rehabilitation measures on ecological infrastructure in response to acid mine drainage from coal mining. Ecol. Eng. 95 463-474. https://doi. org/10.1016/j.ecoleng.2016.06.070

DENMAN L, MAY PB and BREEN PF (2006) An investigation of the potential to use street trees and their root zone soils to remove nitrogen from urban stormwater. Australas. J. Water Resour. 10 (3) 303-311. https://doi.org/10.1080/13241583.2006.11465306

DIETZ AC and SCHNOOR JL (2001) Advances in phytoremediation. Environ. Health Perspect. 109 163-168. https://doi.org/10.1289/ ehp.01109s1163

FAMULARI S (2011) The Phytoremediation Plant Index. URL: http:// www.steviefamulari.net/phytoremediation/index.php (Accessed 17 March 2020).

FARRELL C, SZOTA C, WILLIAMS NSG and ARNDT SK (2013) High water users can be drought tolerant: using physiological traits for green roof plant selection. Plant Soil. 372 (1-2) 177-193. https://doi. org/10.1007/s11104-013-1725-x

GHOSH M and SINGH SP (2005) A comparative study of cadmium phytoextraction by accumulator and weed species. Environ. Pollut. 133 (2) 365-371. https://doi.org/10.1016/j.envpol.2004.05.015

GOVENDER T, BARNES JM and PIEPER CH (2011) Contribution of water pollution from inadequate sanitation and housing quality to diarrheal disease in low-cost housing settlements of Cape Town, South Africa. Am. J. Public Health. 101 (7) 4-9. https://doi. org/10.2105/AJPH.2010.300107

HATT BE, FLETCHER TD and DELETIC A (2009) Hydrologic and pollutant removal performance of stromwater bofiltration systems at the field scale. J. Hydrol. 365 310-321. https://doi.org/10.1016/j. jhydrol.2008.12.001

HENDERSON C, GREENWAY M and PHILLIPS I (2007) Removal of dissolved nitrogen, phosphorus and carbon from stormwater by biofiltration mesocosms. Water Sci. Technol. 55 (4) 183-191. https:// doi.org/10.2166/wst.2007.108

HUFNAGEL C and ROTTLE N (2014) Introduction and overview. In: Selecting Green Infrastructure Stormwater Controls. Water Environment Federation, Alexandria.

ISSG (Invasive Species Specialist Group) (2020) Global Invasive Species Database. URL: http://www.issg.org/ (Accessed 20 July 2020).

IUCN (International Union for Conservation of Nature) (2020) Red List of Threatened Species. URL: https://www.iucnredlist.org/ (Accessed 17 July 2020). 
JACKLIN DM, BRINK IC and JACOBS SM (2021) Exploring the use of indigenous Western Cape plants as potential water and soil pollutant phytoremediators with a focus on green infrastructure. Water SA. 47 (3) 317-325.

KITHA J and LYTH A (2011) Urban wildscapes and green spaces in Mombasa and their potential contribution to climate change adaptation and mitigation. Enviro. Urbanization. 23 (1) 251-265. https://doi.org/10.1177/0956247810396054

LE MAITRE DC, O'FARRELL PJ and REYERS B (2007) Ecosystems services in South Africa: A research theme that can engage environmental, economic and social scientists in the development of sustainability science? S. Afr. J. Sci. 103 (9-10) 367-376.

LEGUIZAMO MAO, GOMEZ WDF and SARMIENTO MCG (2017) Native herbaceous plant species with potential use in phytoremediation of heavy metals, spotlight on wetlands - A review. Chemosphere. 168 1230-1247. https://doi.org/10.1016/j.che mosphere.2016.10.075

MALAN M, MÜLLER F, CYSTER L, RAITT L and AALBERS J (2015) Heavy metals in the irrigation water, soils and vegetables in the Philippi horticultural area in the Western Cape Province of South Africa. Environ. Monit. Assess. 187 (1) 1-8. https://doi.org/10.1007/ s10661-014-4085-y

MCGRATH SP and ZHAO FJ (2003) Phytoextraction of metals and metalloids from contaminated soils. Curr. Opin. Biotechnol. 14 (3) 277-282. https://doi.org/10.1016/S0958-1669(03)00060-0

MEAGHER RB (2000) Phytoremediation of toxic elemental and organic pollutants. Curr. Opin. Plant Biol. 3 (2) 153-162. https://doi. org/10.1016/S1369-5266(99)00054-0

MONTES C, RENDÓN-MARTOS M, VARELA L and CAPPA M (2007) Mediterranean wetland restoration manual. Ministry of Environment, Seville.

NOMQUPHU W, BRAUNE E and MITCHELL S (2007) The changing water resources monitoring environment in South Africa. S. Afr. J. Sci. 103 (7-8) 306-310.

OBERHOLSTER PJ and ASHTON PJ (2008) State of the nation report: An overview of the current status of water quality and eutrophication in South African rivers and reservoirs. Council for Scientific and Industrial Research (CSIR), Pretoria.

OVERSBY B, PAYNE EGI, FLETCHER TD, BYLEVELD G and HATT BE (2014) Vegetation guidelines for stormwater biofilters in the south-west of Western Australia. Water for Liveability Centre, Melbourne.

PASQUINI L and ENQVIST JP (2019) Green infrastructure in South African cities. Report for CSP, African Centre for Cities, National Treasury, South Africa.

PAULEIT S, HANSEN R, RALL EL, ZÖLCH T, ANDERSSON E, LUZ AC, SZARAZ L, TOSICS I and VIERIKKO K (2017) Urban landscapes and green infrastructure. In: Shugart (ed.) Oxford Research Encyclopedia of Environmental Science. Oxford University Press, New York. https://doi.org/10.1093/acrefore/9780199389414.013.23

PAYNE EGI, HATT BE, DELETIC A, DOBBIE MF, MCCARTHY DT and CHANDRASENA GI (2015) Adoption guidelines for stormwater biofiltration systems - summary report. Cooperative Research Centre for Water Sensitive Cities, Melbourne.

PEUKE AD and RENNENBERG H (2006) Heavy metal resistance and phytoremediation with transgenic trees. In: Fladung $M$ and Ewald D (eds) Tree Transgenesis. 137-155. Springer, Berlin. https://doi. org/10.1007/3-540-32199-3_7

POSTEL SL and THOMPSON BH (2005) Watershed protection: Capturing the benefits of nature's water supply services. Nat. Resour. For. 29 (2) 98-108. https://doi.org/10.1111/j.1477-8947.2005.00119.x

PRASAD MNV (2004) Phytoremediation of metals in the environment for sustainable development. Proc. Indian Natl Sci. Acad. 71 (1) 71-98.

RANDOM HARVEST (2020) South African Indigenous Plant Catalogue (SAIPC). URL: https://www.randomharvest.co.za/SouthAfrican-Indigenous-Plants (Accessed 20 July 2020).

READ J, WEVILL T, FLETCHER TD and DELETIC A (2008) Variation among plant species in pollutant removal from stormwater in biofiltration systems. Water Res. 42 (4-5) 893-902. https://doi. org/10.1016/j.watres.2007.08.036

READ J, FLETCHER TD, WEVILL T and DELETIC A (2010) Plant traits that enhance pollutant removal from stormwater in biofiltration systems. Int. J. Phytoremed. 12 (1) 34-53. https://doi. org/10.1080/15226510902767114
RICHARDSON DM, FOXCROFT LC, LATOMBE G, LE MAITRE DC, ROUGET M and WILSON JR (2020) The biogeography of South African terrestrial plant invasions. In: Van Wilgen BW, Measey J, Richardson DM, Wilson JR and Zengeya TA (eds.) Biological Invasions in South Africa. Springer, Cham. https://doi. org/10.1007/978-3-030-32394-3_3

ROBINSON BH, ANDERSON CWN and DICKINSON NM (2015) Phytoextraction: Where's the action? J. Geochem. Explor. 151 34-40. https://doi.org/10.1016/j.gexplo.2015.01.001

ROCA M, ESCARAMEIA M, GIMENO O, DE VILDER L, SIMM JD, HORTON B and THORNE C (2017) Green Approaches In River Engineering - Supporting Implementation of Green Infrastructure. HR Wallingford, Oxfordshire.

RODRÍGUEZ-ECHEVERRÍA S (2009) Soil organisms: the invisible dimension in the invasion by exotic plant species. Ecosistemas. 18 (2) $32-43$.

RSA (Republic of South Africa) (2004) National Environmental Management: Biodiversity Act (No. 10 of 2004). Department of Environmental Affairs (DEA), Pretoria.

SALT DE, SMITH RD and RASKIN I (1998) Phytoremediation. Annu. Rev. Plant Physiol. Plant Molec. Biol. 49 (1) 643-668. https://doi. org/10.1146/annurev.arplant.49.1.643

SANBI (South African National Biodiversity Institute) (2020a) Plants of Southern Africa. URL: http://posa.sanbi.org/sanbi/Explore (Accessed 15 July 2020).

SANBI (South African National Biodiversity Institute) (2020b) Red List of South African Plants. URL: http://redlist.sanbi.org/ (Accessed 15 July 2020).

SANBI (South African National Biodiversity Institute) (2020c) South African National Biodiversity Institute, Threatened Species Programme. URL: https://www.inaturalist.org/projects/redlist-s-afr (Accessed 15 July 2020).

TANNER P and MÖHR-SWART M (2007) Guidelines for the rehabilitation of mined land. Chamber of Mines of South Africa/Coal Tech, Johannesburg.

TERRY N and BAÑUELOS GS (1999) Phytoremediation of Contaminated Soil and Water. CRC Press, Boca Raton.

VISOOTTIVISETH P, FRANCESCONI K and SRIDOKCHAN W (2002) The potential of Thai indigenous plant species for the phytoremediation of arsenic contaminated land. Environ. Pollut. 118 (3) 453-461. https://doi.org/10.1016/S0269-7491(01)00293-7

VAN WILGEN BW, RICHARDSON DM, LE MAITRE DC, MARAIS C and MAGADLELA D (2001) The economic consequences of alien plant invasions: examples of impacts and approaches to sustainable management in South Africa. Environ. Dev. Sustainability. 3 (2) 145-168. https://doi.org/10.1023/A:1011668417953

VAN WILGEN BW, MEASEY J, RICHARDSON DM, WILSON JR and ZENGEYA TA (2020) Biological invasions in South Africa: an overview. In: Van Wilgen BW, Measey J, Richardson DM, Wilson JR and Zengeya TA (eds.) Biological Invasions in South Africa. Springer, Cham. https://doi.org/10.1007/978-3-030-32394-3

WERTZ-KANOUNNIKOFF S, LOCATELLI B, WUNDER $S$ and BROCKHAUS M (2011) Ecosystem-based adaptation to climate change: What scope for payments for environmental services? Clim. Dev. 3 (2) 143-158. https://doi.org/10.1080/17565529.2011.582277

WIRTH P, CHANG J, SYRBE RU, WENDE W and HU T (2018) Green infrastructure: a planning concept for the urban transformation of former coal-mining cities. Int. J. Coal Sci. Technol. 5 (1) 78-91. https://doi.org/10.1007/s40789-018-0200-y

WONG THF (2006) Austalian runoff quality: a guide to water sensitive urban design. National Committee on Water Engineering, New South Wales.

YANG B, LI S, WALL HA, BLACKMORE P and WANG Z (2015) Green infrastructure design for improving stormwater quality: Daybreak community in the United States West. Landscape Architect. Front. 3 (4) $12-22$.

ZENGEYA TA and WILSON JR (2020) The status of biological invasions and their management in South Africa in 2019. (Second order draft). South African National Biodiversity Institute, Kirstenbosch and DSI-NRF Centre of Excellence for Invasion Biology, Stellenbosch. 